\title{
Introduction
}

\section{Helge Hvid}

andom events can create patterns. Texts with totally independent origin may give rise to transverse reflections. This introduction is not a presentation of the individual article on its own merits, but rather a presentation of reflections that the articles raise. The individual articles are introduced in the abstracts that initiate the articles.

In the introduction to the last issue of the journal (13/3) Jan Karlsson warns against blind faith in the basic assumptions of the Nordic working life research. One example is the uncritical belief in autonomy at work as a means for better productivity and better quality of working life, which can be misleading. This issue is, however, not an uncritical celebration of Nordic working life and the values behind. On the contrary, there is one visible thread that goes through the five articles presented in this issue that can be expressed as follows: "It could have been so nice, but it is actually quite bad." All the articles demonstrate how difficult it is to realize basic values of Nordic working life at the micro-level. Yet, they also to a certain extent point at options to restore these values.

Kenn Warming examines one of the great challenges for gender equality in the Nordic labor markets: the large gender segregation. The labor market is divided into jobs for men and jobs for women. In Denmark, one of the countries with the largest gender segregation, six out of ten are working in jobs that are clearly dominated by one sex or the other. Thereby, gender inequality is transformed to inequality between sectors. There has been a focus on how to attract men to the female-dominated sectors and vice versa. Kenn Warming notes, however, that many of the men, who come into the women-dominating care sector, leave the profession rather quickly. Men encounter mistrust in relation to their professionalism. They are confronted with questions about whether men in care work are "real men." Some men are suspected of having hidden sexual motives for being in the sector. This positioning of men along with the general deterioration of working conditions in the sector gets the men to leave the sector.

Malgorzata Lahti examines a similar covert discrimination following ethnic boundaries: she examines how highly educated Russian women at Finnish workplaces are positioned through daily communication at the workplace, a positioning that is disadvantageous for the Russian women. According to Malgorzata Lahti, this positioning is not a result of a clash between two firmly established cultures. The positioning is created through communicative processes in the workplace. Kenn Warming and Malgorzata Lahti take different theoretical positions, but common for them is that they study how inequality is reproduced in the egalitarian Nordic countries. And common for them is that they find explanations in the communication in daily work. None of them have explicit recommendations on what can be done to avoid inequality and discrimination, but they make the phenomenon visible. 
Nina Amble also studies women's work. Her article is based on years of participation in the development of work in social care. She has taken part in a development of care work that was based on the Scandinavian sociotechnical tradition. However, it was necessary to develop this tradition, which originally focused on industrial work, to include relational care work. An important theoretical point of Amble is that the focus on autonomy in the job, which has been very important in understanding the psychological working environment, is not sufficient. This must be combined with "responsible autonomy" in the work organization, which actually also is part of the sociotechnical tradition. Therefore, she and her colleagues have created opportunities for care workers to meet regularly, develop their work organization based on practical experiences, and set practice-related professional standards. She shows in her article that the socio-technic is as relevant today as it was 50 years ago, but that it must be adapted to emerging sectors and to changing conditions in the work. However, if the sociotechnic has these qualities, why isn't it spread by itself in the Nordic countries and elsewhere? Amble answers this question with a quote from Trist, one of the fathers of sociotechnic. He states that both employers and trade unions avoid the sociotechnic, even though it can improve efficiency and make a better working life. Trist finds that in the choice between control over the people and efficiency, the owners choose control. The unions give priority to a free, critical position opposite employers. The dissemination of the sociotechnic is limited by the established balance of power in society, a balance of power which is constantly shifting and which constantly closes opportunities and constantly offers new possibilities for the basic ideas of the sociotechnic.

Johan Simonsen Abildgaard and Niels Christian Mossfeldt Nickelsen's article has parallels with that of Ambles, and is at the same time very different. Johan Simonsen Abildgaard and Niels Christian Mossfeldt Nickelsen are, like Amble, critical toward some of the key concepts in the understanding of psychosocial work environment and the quality of working life. They are critical to concepts such as autonomy, influence, and social support because they are abstract, and because they are not sensitive to the specific context of work. They challenge the established concepts in the field of working environment by an Actor Network Theory (ANT) approach. Exemplified by working as a postman, they show how the material has a practical intentionality, and they show how the demands, control, and social support can only be understood in a very contextspecific manner. They find that the general recommendations for the development of work have a limited value. Johan Simonsen Abildgaard and Niels Christian Mossfeldt Nickelsen are, however, also aware of a limitation in their own work: if everything dissolves in context, how can societal and political efforts to improve working conditions be established? I find that Amble has quite a simple answer to that question: the answer is to provide people living in a given context opportunities to develop their "sociomaterial world," as it is called in ANT or their "sociotechnical world" as it is called in sociotechnique. Perhaps the ANT tradition, which is generally very little action oriented, can challenge the sociotechnical tradition, which is generally very pragmatic and action oriented. And vice versa?

Anna Ilsøe treats another major challenge for the Nordic working life: the declining support to the traditional trade unions among employees. The Nordic welfare states and labor market conditions are largely based on conflict regulation between strong labor market organizations (unions and employers' associations). In Denmark, as in the other Nordic countries, the membership rate of the traditional trade unions has for quite 
many years been falling. In 1995 the membership rate of the traditional trade union movement was $70 \%$ of the employees. In 2012, the membership rate of the traditional unions dropped to about $60 \%$. During the same period, the membership rate of the alternative unions increased from a few percent to almost $10 \%$. Anna Ilsøe examines what the unions can locally do to curb this trend. Should the shop stewards use a push strategy, where those who aren't members of the traditional unions are excluded from the benefits gained through collective agreements, or should the shop stewards follow a pull strategy, where they demonstrate the positive results created by the unions also for those who are outside? The answer is not simple. Both strategies have their positive and negative aspects. However, Anna Ilsøe demonstrates that there are great potentials in deliberate recruitment strategy at the enterprise level.

The five articles in the current issue point individually and together to weaknesses in the Nordic working life. They do, however, also individually and together highlight possibilities to counter these weaknesses. 